\title{
Noonan Syndrome and Systemic Lupus Erythematosus: Association or Risk Factor?
}

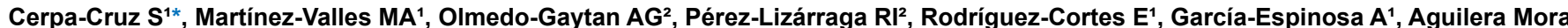

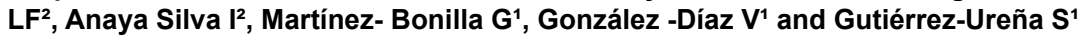

${ }^{1}$ Rheumatology and Immunology Department, Civil de Guadalajara "Fray Antonio Alcalde" Jalisco, Mexico

IInternal Medicine Department, Hospital Civil de Guadalajara "Fray Antonio Alcalde" Jalisco, Mexico

\begin{abstract}
Aim: The RAS/MAPK signaling pathway proteins with germline mutations in their respective genes are associated with several disorders such as Noonan, LEOPARD, neurofibromatosis type 1, Costello and cardio-facio-cutaneous syndromes. Some monogenic conditions are associated with the development of systemic lupus erythematosus (SLE), in medical literature are few reports that describe the association of RAS opathies and autoimmune disease. Our aim was to describe the clinical picture of a patient with diagnosis of Noonan and SLE.
\end{abstract}

Methods: We report a clinical case of a 24-year-old woman with Noonan syndrome who developed SLE according to American College of Rheumatology criteria for the classification of SLE. The patient had arthritis, serositis, lymphopenia, proteinuria, high levels of antinuclear antibodies and anti-ds DNA positive. This rare association then driven to search the medical literature for English articles on the subjects of Noonan and SLE in Pubmed.

Results: Our patient had oligoarthritis, serositis, Iymphopenia, ISN/RPS Class IV lupus nephritis, ANA 1:1280 homogeneous pattern and anti-dsDNA antibodies very similar to the 8 patients already reported in literature.

Conclusion: There are nine cases reported with the association of two rare diseases, Noonan syndrome and SLE, this connection could suggests that RAS opathies may be a risk factor to the development of autoimmune disorders.

\section{Introduction}

In 1962, Jacqueline Noonan, a pediatric cardiologist, presented at the Midwest Society for Pediatric Research a clinical study describing nine patients who shared distinctive facial features including hypertelorism, downslanting palpebral fissures, low set posteriorly rotated ears, ptosis and malar hypoplasia. In addition short stature, pulmonary stenosis, cryptorchidism and chest deformities were observed. A few years later, in 1968, Dr Noonan published additional 10 patients descriptions being the first to indicate that this disorder associated with congenital heart defects occurred in both genders, was associated with normal chromosomes [1].

Noonan syndrome (NS) is a relatively common congenital genetic disorder with an estimated prevalence of 1 in 1000 to 1 in 2500 live births. It is an autosomal dominant disorder with complete penetrance but variable expressivity. Until recently, diagnosis was based solely on clinical findings, but a genetic mutation is identifiable in $61 \%$ of the patients [2].

NS is genetically heterogeneous, and nine genes that participate in the rat sarcoma/mitogen-activated protein kinases (RAS/ MAPK) pathway (PTPN11, SOS1, KRAS, NRAS, RAF1, BRAF, SHOC2, MEK1 and $C B L$ ) have been causally linked to this trait or closely related conditions. These diseases have been grouped into a single family, which has been termed the neuro-cardio-facial-cutaneous syndrome family (or, alternatively, the RAS-opathies) [3].

Systemic lupus erythematosus (SLE) is the prototypic systemic autoimmune disease characterized by heterogeneous, multisystem involvement and the production of an array of serum autoantibodies. Clinical features in individual patients can be quite variable, ranging from mild joint and skin involvement to severe, life-threatening internal organ disease. In the last decade, several studies support the role of multiple susceptibility genes in the development of SLE [4].
The association of NS and autoimmune disorders, such as thyroiditis, vasculitis, vitiligo, celiac disease or anterior uveitis, and SLE has been reported in isolated cases or case series in the past decades $[5,6]$.

As far as we know there are eight reported patients with NS and SLE in the literature, we report the case of a young woman with a concomitant diagnosis of NS and LES serving to further investigations to identify an increasingly recognizable association between NS and other autoimmune diseases including SLE.

\section{Case Report}

A 24-year-old woman was admitted to the Internal Medicine Department for the management of anemic syndrome. Three months before admission she presented hiporexia, headache and exertional dyspnea, intermittent fever and a loss of 22 pounds (about 10 kilograms) was estimated since the beginning of her symptoms. Two weeks before admission bilateral knee pain, ankle oadema, dry cough and progressive dyspnea reaching minimal efforts appeared. At admission severe anaemia ( $\mathrm{Hb} 6.71 \mathrm{gr} / \mathrm{dL})$ and leucopenia $\left(2860 \mathrm{cels} / \mathrm{mm}^{3}\right)$ were observed and prompted a peripheral blood and blood marrow aspirate examination by the hematology department, founding mild global hypocellularity, leucopenia and granulocytic hypoplasia, and also

*Corresponding author: Cerpa-Cruz S, Rheumatology and Immunology Department, Civil de Guadalajara "Fray Antonio Alcalde" Jalisco, Mexico, E-mail: sacer04@prodigy.net.mx

Received June 17, 2013; Accepted August 21, 2013; Published August 27, 2013

Citation: Cerpa-Cruz S, Martínez-Valles MA, Olmedo-Gaytan AG, PérezLizárraga RI, Rodríguez-Cortes E, et al. (2013) Noonan Syndrome and Systemic Lupus Erythematosus: Association or Risk Factor? Int J Genomic Med 1: 107. doi:10.4172/2332-0672.1000107

Copyright: (c) 2013 Cerpa-Cruz S, et al. This is an open-access article distributed under the terms of the Creative Commons Attribution License, which permits unrestricted use, distribution, and reproduction in any medium, provided the original author and source are credited. 
Citation: Cerpa-Cruz S, Martínez-Valles MA, Olmedo-Gaytan AG, Pérez-Lizárraga RI, Rodríguez-Cortes E, et al. (2013) Noonan Syndrome and Systemic Lupus Erythematosus: Association or Risk Factor? Int J Genomic Med 1: 107. doi:10.4172/2332-0672.1000107

Page 2 of 5

notice the presence of LE cells in both direct marrow and peripheral blood smears. A serological test for HVI, hepatitis B and C viruses were negative.

A Rheumatologist assessment was requested because of anemia, lymphopenia, bilateral knee arthritis and the presence of LE cells. The patient was a previously healthy young pleasant woman. The family history did not reveal any known genetic or rheumatologic disorder. The past medical history also reveals hair loss during the last three months but no other dermatologic lesion was observed by the patient. In addition to moderate painful arthritis of the knees, the physical examination was relevant to demonstrate multiple phenotypic traits and a Geneticist evaluation was also requested. No similar phenotypical abnormalities were observed in parents or first degree relatives through direct observation or by photography means. She was born from a nine-month normal fifth pregnancy by vaginal delivery. The growth and development was normal, with secondary sex characteristics and menarche appearances at the usual age. No intellectual disabilities were observed, although not tested, the patient appeared to have normal intelligence. The physical examination reveals short stature (with $<3$ centile of height achieved at age 19 years recorded in a vaccineimmunization schedule), slightly curly hair with a high hairline giving the appearance of a broad forehead, mild low-set ears implantation, sparse eyebrows, bilateral telecanthus with no deviation of the palpebral fissure, mild bilateral ptosis, broad short neck with mild bilateral neckwebbing, deep groove philtrum, high arched palate, micrognatia, absent uvula and lingual frenulum and crowded teeth. The nipples appears widely spaced and a chest roentgenogram shown a moderate pectus excavatum. No morphological abnormalities were apparent in the upper and lower extremities, or genitalia. An electrocardiogram shown sinus tachycardia and left axis deviation. A transthoracic echocardiography reported mild mitral and tricuspid insufficiency with mild pulmonary arterial hypertension and small pericardial effusion without hemodynamic repercussion. A chromosomal analysis demonstrated a normal $46 \mathrm{XX}$ karyotype and the diagnosis of Noonan syndrome was made on the basis of clinical findings according to the criteria proposed by van der Burgt et al. [7]. At the same time an extensive laboratory assessment was taken (Table 1). Posteroanterior chest X-ray shown bilateral pleural effusion with posterior aspirate liquid analysis being exudative one.

The patient was diagnosed with SLE according to the American College of Rheumatology classification criteria (arthritis, serositis, lymphopenia, proteinuria greater than 0.5 gr per day, high levels of antinuclear antibodies and anti-ds DNA) [8]. We performed real-time ultRASound-guided renal biopsy revealing Class IV International Society of Nephrology/Renal Pathology Society (ISN/ RPS) classification lupus nephritis [9]. The patient was treated with 1000 mgs metylprednisolone pulses for three consecutive days followed by prednisone $1 \mathrm{mg} / \mathrm{kg}$ /day with tapered indication after few weeks plus $0.75 \mathrm{~g} / \mathrm{m}^{2}$ of cyclophosphamide on day one. The blood cell count started to rise soon after the treatment has begun and the pleural effusions resolved without any other particular treatment. The patient is actually receiving monthly high dose cyclophosphamide.

\section{Discussion}

The heterogeneous clinical features of NS are characterized by distinctive facial features, short stature, chest deformity, congenital heart disease, other malformations and variable levels of mental retardation. It is important to notice that even when the phenotype becomes very striking in early childhood, with advancing age, it may again become quite subtle [2]. The variable phenotypic expression and correlation between disease phenotype and genetic heterogeneity have been well established and less severe cases may go unnoticed for many years as in our reported patient.

The first evidence for autoimmunity in patients with NS was described by Vesterhus et al. who reported an increased prevalence of autoimmune thyroiditis in patients with NS [10]. Since the first report of NS and SLE in a 20-year-old patient was reported by Martin et al. [11] some other reports for this association has been recognized in the last decade (Table 2). A slightly predominance of female patients with NS and LES ( 5 female/4 male) has been observed which is below the female-to-male ratio reported in children, adults, and older people.

\begin{tabular}{|c|c|c|}
\hline Variable & During Hospitalization & Reference Range \\
\hline White-cell count (per $\mathrm{mm}^{3}$ ) & 2860 & $4500-1000$ \\
\hline Lymphocytes (\%) & 16 & $22-44$ \\
\hline Hemoglobin (g/dl) & 6.7 & $12.0-16$ \\
\hline Platelet count (per $\mathrm{mm}^{3}$ ) & 234,000 & $150,000-400,000$ \\
\hline Erythrocyte sedimentation rate $(\mathrm{mm} / \mathrm{hr})$ & 18 & $1-20$ \\
\hline C-reactive protein (mg/dl) & 0.5 & $<1.0$ \\
\hline Haptoglobin (mg/dl) & 12 & $30-200$ \\
\hline Direct Coomb Test & Positive $3+$ & Negative \\
\hline Aspartate aminotransfeRASe (U/liter) & 97 & $9-32$ \\
\hline Alanine aminotransfeRASe (U/liter) & 32 & $7-30$ \\
\hline Lactate dehydrogenase (U/liter) & 1000 & $110-210$ \\
\hline Complement C3 (mg/dl) & 49 & $88-200$ \\
\hline Complement C4 (mg/dl) & 6.4 & $12-70$ \\
\hline Rheumatoid Factor & Negative & Negative \\
\hline Urine protein $24 \mathrm{hr}$ & 980 & $<150 \mathrm{mg} / 24 \mathrm{hr}$ \\
\hline Antinuclear antibody (Hep2 cells substrate) & $1: 1280$ homogenous pattern & Negative at 1:40 dilution \\
\hline Anti-double-stranded DNA (Ul/ml) & 42 & $<5.5$ \\
\hline Anti-thyroid peroxidase antibodies (UI/ml) & 1850 & $<5$ \\
\hline Anti-thyroglobulin antibodies (IU/ml) & 340 & $0-100$ \\
\hline Thyrotropin $(\mu \mathrm{U} / \mathrm{ml})$ & 4.4 & $0.5-4.7$ \\
\hline Thyroxine (free) (ng/dl) & 2.2 & $0.8-2.8$ \\
\hline
\end{tabular}

Table 1: Laboratory Data 
Citation: Cerpa-Cruz S, Martínez-Valles MA, Olmedo-Gaytan AG, Pérez-Lizárraga RI, Rodríguez-Cortes E, et al. (2013) Noonan Syndrome and Systemic Lupus Erythematosus: Association or Risk Factor? Int J Genomic Med 1: 107. doi:10.4172/2332-0672.1000107

Page 3 of 5

\begin{tabular}{|c|c|c|c|c|c|c|}
\hline Sex & $\begin{array}{c}\text { Age at NS } \\
\text { diagnosis/SLE onset }\end{array}$ & Noonan Syndrome Features & SLE features & $\begin{array}{l}\text { Other autoimmune } \\
\text { manifestations }\end{array}$ & $\begin{array}{l}\text { Affected } \\
\text { Gene }\end{array}$ & Reference \\
\hline $\mathrm{F}$ & $24 \mathrm{y} / 24 \mathrm{y}$ & $\begin{array}{l}\text { Short stature, facial dysmorphism, } \\
\text { cardiac abnormalities }\end{array}$ & $\begin{array}{l}\text { Oligoarthritis, serositis, lymphopenia, ISN/ } \\
\text { RPS Class IV lupus nephritis, ANA 1:1280 } \\
\text { homogeneous pattern and anti-dsDNAAb }\end{array}$ & $\begin{array}{l}\text { Anti-TPO and anti } \\
\text { thyroglobulin } \mathrm{Ab}\end{array}$ & NT & Present Case \\
\hline M & $10 y / 13 y$ & $\begin{array}{l}\text { Short stature, facial dysmorphism, } \\
\text { darkly pigmented skin and sparse } \\
\text { hair }\end{array}$ & $\begin{array}{c}\text { Polyarthritis, serositis (pericardial), ANA } \\
1: 800, \text { positive anti-ds DNA Ab and lupus } \\
\text { anticoagulant }\end{array}$ & $\begin{array}{l}\text { Massive } \\
\text { lymphadenopathy and } \\
\text { hepatosplenomegaly }\end{array}$ & $\mathrm{SHOC} 2$ & $\begin{array}{l}\text { Bader-Meunier B et } \\
\quad \text { al (Ref 13) }\end{array}$ \\
\hline $\mathrm{F}$ & Not reported / 32 y & Not reported & $\begin{array}{c}\text { Photosensitivity, arthritis, lymphopenia and } \\
\text { ANA 1:320 homogeneous pattern }\end{array}$ & $\begin{array}{c}\text { Autoimmune } \\
\text { hypothyroidism }\end{array}$ & PTPN11 & $\begin{array}{c}\text { Quaio CR et al (Ref } \\
16)\end{array}$ \\
\hline $\mathrm{F}$ & $3 y / 18 y$ & $\begin{array}{l}\text { Short stature, facial dysmorphism, } \\
\text { pectus excavatum, hypertrophic } \\
\text { cardiomyiopathy, psychomotor } \\
\text { retardation. }\end{array}$ & $\begin{array}{l}\text { Polyarthritis, papillary RASh on lower } \\
\text { limbs, Coombs positive hemolytic anemia, } \\
\text { lymphopenia, thrombocytopenia. ANA } \\
>1: 40, \text { high anti dsDNAAb and IgM } \\
\text { anticardiolipin. }\end{array}$ & None & KRAS & $\begin{array}{l}\text { Leventopoulus G et } \\
\text { al (Ref 28) }\end{array}$ \\
\hline M & Not reported / 28 y & $\begin{array}{l}\text { Short stature, facial dysmorphism, } \\
\text { pectus excavatum, pulmonary valve } \\
\text { stenosis, bilateral cryptorchidism }\end{array}$ & $\begin{array}{l}\text { Polyarthritis, lymphopenia, serositis } \\
\text { (pericardial), ANA 1:640 speckled pattern }\end{array}$ & $\begin{array}{l}\text { Autoimmune primary } \\
\text { hypothyroidism }\end{array}$ & NT & $\begin{array}{l}\text { Lisbona MP et al } \\
\quad \text { (Ref 27) }\end{array}$ \\
\hline $\mathrm{F}$ & $3 \frac{1}{2} y / 5 y$ & $\begin{array}{l}\text { Short stature, facial dysmorphism, } \\
\text { shield-like chest with mild pectus, } \\
\text { multiple long bone deformities, mild } \\
\text { septal cardiac thickening, cognitive } \\
\text { function in the low borderline range }\end{array}$ & $\begin{array}{l}\text { Arthritis, serositis, thrombocytopenia, } \\
\text { Coombs positive hemolytic anemia, } \\
\text { WHO Class IV lupus nephritis, ANA } \\
\text { 1:1260, raised anti-dsDNA Ab and IgG } \\
\text { anticardiolipin Ab. }\end{array}$ & None & $\begin{array}{c}\text { PTPN11 } \\
\text { test was } \\
\text { negative. } \\
\text { Rest NT. }\end{array}$ & $\begin{array}{l}\text { Lopez-Rangel E. et } \\
\quad \text { al (Ref 26) }\end{array}$ \\
\hline M & $8 y / 8 y$ & $\begin{array}{l}\text { Short stature, facial dysmorphism, } \\
\text { short webbed neck, joint } \\
\text { hiperextensibility, pulmonary valve } \\
\text { stenosis, mild mental retardation }\end{array}$ & $\begin{array}{c}\text { Arthritis, oral ulcers, thrombocytopenia, } \\
\text { ANA 1:40, anti-dsDNA Ab, elevated IgG } \\
\text { anticardiolipin Ab, WHO Class I lupus } \\
\text { nephritis }\end{array}$ & None & NT & $\begin{array}{c}\text { Alanay } Y \text { et al (Ref } \\
25)\end{array}$ \\
\hline $\mathrm{F}$ & Infancy / 26 y & $\begin{array}{l}\text { Short stature, facial dysmorphism, } \\
\text { pectus carinatum, cardiac } \\
\text { abnormalities, hepato - } \\
\text { esplenomegaly, epilepsy, mental } \\
\text { retardation }\end{array}$ & $\begin{array}{l}\text { Artharlgias, lymphopenia, hemolytic } \\
\text { anemia, ANA 1:640 homogeneous } \\
\text { pattern, positive anti-dsDNS Ab, anti-SM, } \\
\text { Lupus anticoagulant and IgG and IgM } \\
\text { anticardiolipin Ab }\end{array}$ & $\begin{array}{l}\text { Autoimmune } \\
\text { thyroiditis, celiac } \\
\text { disease. }\end{array}$ & NT & $\begin{array}{l}\text { Amoroso A et al } \\
\quad(\text { Ref } 6)\end{array}$ \\
\hline M & $20 y / 17 y$ & $\begin{array}{c}\text { Short stature, facial dysmorphism, } \\
\text { pectus excavatum, poorly developed } \\
\text { secondary sexual characteristics, } \\
\text { mitral valve disease. }\end{array}$ & $\begin{array}{l}\text { Polyarthritis, oral ulcers, serositis } \\
\text { (pericardial and pleural), renal insufficiency, } \\
\text { ANA 1:2560 peripheral pattern. }\end{array}$ & None & NT & $\begin{array}{l}\text { Martin DM et al } \\
\quad(\text { Ref } 11)\end{array}$ \\
\hline
\end{tabular}

SLE: Systemic Lupus Erythematosus; ANA: Antinuclear Antibodies; Anti-dsDNA: Anti-double strained DNA; Ab: Antibodies; Anti-TPO: Anti Thyroid Peroxidase; ISN/RPS: International Society of Nephrology/Renal Pathology Society; NT: Not Tested

\section{Table 2: Description of Noonan syndrome patients with associated SLE diagnosis.}

The age at SLE onset in the published cases including our patient has been in the range of 5-26 years and in six patients the diagnosis was made in the peak incidence age reported for SLE (sixty-five percent of patients with SLE have disease onset between the ages of 16 and 55) [12]. In almost half of the reported cases lupus nephritis was observed. In one case a WHO Class I lupus nephritis was observed which is rarely, if ever, diagnosed because these patients typically have a normal urinalysis, no or minimal proteinuria, and a normal serum creatinine. In the remaining two patients with biopsy proven lupus nephritis including our case, diffuse glomerulonephritis were observed (WHO class IV or ISN/RPS class IV) which is the most common and most severe form of lupus nephritis. Antinuclear antibodies can produce different staining patterns reflecting the presence of antibodies to one or some nuclear antigens. The homogeneous staining was the most prevalent pattern observed in three patients including the present case. The homogeneous pattern reflects antibodies to the DNA-histone complex. It is believed that these antibodies are responsible for the LE phenomenon which was observed in the present case and prompted to an early diagnosis of SLE. In a recent article, Bader-Meunier et al. [13] pointed out that SLE observed in patients with RAS opathies may differ from "classic" SLE in part because of the high frequency of pericarditis (4/8 patients) observed in the former cases. Pericardial involvement in the form of effusion occurs in over $50 \%$ of SLE patients at some point of the disease. Pericarditis may be the initial manifestation in SLE patients but pericardial disease is usually asymptomatic. It is generally diagnosed by echocardiography performed for some other reason, such as suggestive electrocardiographic abnormalities or because as in the present case, a high prevalence of cardiac abnormalities observed in NS patients [14].

Interestingly a growing number of cases linking autoimmune disorders other than SLE with NS have been described including: celiac disease, vitiligo, autoimmune thyroiditis, anterior uveitis and antiphospholipid syndrome $[5,6,15]$. In a recent large cohort of NS patients and related disorders evaluated for autoimmune disases and multiple antibodies reported by Quaio et al. a high prevalence of autoimmune diseases (14\%) fulfilling specific criteria including SLE, autoimmune thyroiditis, celiac disease, primary antiphospholipid syndrome, autoimmune hepatitis and vitiligo were reported. This represents a two to threefold increase in frequency when compared with normal population (5-8\%). They also observed autoimmune antibodies in $52 \%$ of the patients without clinical findings correlation in some patients [16]. In the present case high levels of antinuclear antibodies and anti-DNA were founded and we can classify the patient as having SLE according to ACR criteria. Anti-thyroglobulin and antithyroid peroxidase antibodies have been detected in $20 \%$ and $10 \%$ of NS patients with an increased prevalence in older age [10]. Three of the previously 8 reported patients with NS and SLE has autoimmune hypothyroidism. In the present case we founded high levels of thyroid autoantibodies without clinical or functional correlation until now. We suggest that patients with NS and SLE show be monitored regularly for autoimmune thyroiditis. 
Eight genes in the RAS-MAPK signalling pathway cause Noonan syndrome or closely related conditions. (PTPN11, SOS1, KRAS, NRAS, $R A F 1, B R A F$, SHOC2, and $C B L$ ). In $50 \%$ of cases, Noonan syndrome is caused by missense, gain of function mutations in the PTPN11 region which encodes the protein SHP2 and has been linked to the chromosomal band 12q24.1. [17]. At least 107 PTP family members has been recognized and their function (dephosphorylate tyrosine residues) is a key regulatory mechanism for numerous physiological processes, including many that are crucial for the immune system. Severe phenotypes are also observed in many PTP knock-out mice, and in many cases, the immune system is affected. The SHP2 enzyme has positive role in lymphocyte activation, augments $E R K$ activation that is crucial for lymphoid development [18]. Among other functions the product of PTPN11 is important for the maintenance of resting lymphocytes and regulation of the transcription factor NF-kB, which plays a fundamental role in antibody production and natural killer cells activation [19].

The humoral and cellular immunities play roles in SLE pathogenesis. Many clinical features of SLE result from loss of B-cell tolerance, leading to the development of autoantibodies targeting self-antigens to induce tissue damage. A genetic contribution to human lupus is well established. The strong genetic contribution to the development of SLE is supported by the high heritability of the disease $(>66 \%)$, a higher concordance rate for SLE in monozygotic twins than in dizygotic twins or siblings (24-56\% versus $2-5 \%$, respectively) which was observed over 30 years ago, and the high sibling recurrence risk ratio of patients with SLE (between eightfold and 29-fold higher than in the general population) and up to $10 \%$ of SLE patients have a relative with lupus [20]. Another PTP family member, PTPN22 is a negative regulator for T-cell signal transduction in cellular immunity. It is considered to be the strongest common genetic risk factor for human autoimmunity besides the major histocompatibility complex (MHC) and as an important candidate gene in SLE [21].

Several studies have founded single nucleotide polymorphisms associated with SLE, but only about $15 \%$ of the heritability of SLE to be explained by those loci. Some rare monogenic disorders has been associated with a high risk of SLE, especially pediatric-onset SLE including Aicardi-Goutieres syndrome, spondylenchondrodysplasia, congenital complement deficiencies, chronic granulomatosis disease and a null mutation in the DNASE1L3 gene in the Arab population [22].

Besides PTPN22 known association with autoimmunity, the high frequency of autoimmunity and alterations in the level of immunoglobulins observed in patients harbouring mutations in PTPN11 may, as suggested by Quaio et al. the involvement of other PTPNs, an association that needs to be confirmed [16]. Several studies in animal and human immunologic models have pointed to the complex role of RAS/MAPK signaling pathway in general immunity. $R A S$ is a GTP-binding protein that plays multiple roles in the proliferative and inflammatory responses crucial for the maintenance of immune tolerance. Even when the product of PTPN11, SHP2 has not been reported to be associated with autoimmune diseases, SHP2 acts as a regulator of NF-Kappa B activation, and in concert with SHP1 inhibits NK cell activation, it is possible that mutations of PTPN11 as the observed in NS could contribute to the development of autoimmunity [23]. Linkage analysis on SLE susceptibility loci has been reported including gene mutations in PTPN11 at the 12q24 locus in Hispanic and European American families [24].

Noonan syndrome is a relatively common autosomal dominant disorder, which makes very likely that most doctors will encounter
NS patients during their career, a diagnosis that might be overlooked because presentation can be mild and phenotypical traits can be subtle with age. The association between NS and SLE and other autoimmune diseases has been described in a few cases in the medical literature. The understanding of the molecular genetics causes of NS has experienced enormous progress in the past decade recognizing mutations in the $R A S / M A P K$ as the signaling system involved in NS. T lymphocytes play a critical role in SLE pathogenesis. Since RAS is an essential protein for normal $\mathrm{T}$ lymphocyte function, it is not surprising that dysregulated RAS signaling participates in the genesis of autoimmune diseases reported in patients with RAS opathies including NS and related disorders. The hypothesis of a common origin is strengthen for the linkage of a susceptibility gene for SLE to an area that is also directly involved in the occurrence of RAS ophaty, although no definite study has yet been performed. Until that happens clinicians should be alert about the molecular mechanisms that underlies RAS opathy may predispose to the development of SLE.

\section{References}

1. Noonan JA (2009) History of Noonan syndrome and related disorders. In Noonan syndrome and related disorders - a matter of deregulated RAS signaling. Zenker M [Ed]. Monogr Hum Genet. Basel, Karger, 17: 1-8.

2. Romano AA, Allanson JE, Dahlgren J, Gelb BD, Hall B, et al. (2010) Noonan syndrome: clinical features, diagnosis, and management guidelines. Pediatrics 126: $746-759$

3. Tartaglia M, Gelb BD, Zenker M (2011) Noonan syndrome and clinically related disorders. Best Pract Res Clin Endocrinol Metab 25: 161-179.

4. Deng Y (2013) Genetics of human SLE. In: Dubois' Lupus Erythematosus and Related Syndromes, Wallace DJ, Hahn BH [Eds] Elsevier Saunders, Philadelphia.

5. Svensson J, Carlsson A, Ericsson UB, Westphal O, Ivarsson SA (2003) Noonan syndrome and Autoimmune diseases. J Ped End Met 16: 217-218.

6. Amoroso A, Garzia P, Vadacca M, Galluzzo S, Del Porto F, et al. (2003) The unusual association of three autoimmune diseases in a patient with Noonan syndrome. J Adolesc Health 32: 94-97.

7. van der Burgt I, Berends E, Lommen E, van Beersum S, Hamel B, et al. (1994) Clinical and molecular studies in a large Dutch family with Noonan syndrome. Am J Med Genet 53: 187-191.

8. Hochberg MC (1997) for the Diagnostic and Therapeutic Criteria Committee of the American College of Rheumatology: Updating the American College of Rheumatology revised criteria for the classification of systemic lupus erythematosus letter. Arthritis Rheum 40:1725

9. Weening JJ, D'Agati VD, Schwartz MM, Seshan SV, Alpers CE, et al. (2004) The classification of glomerulonephritis in systemic lupus erythematosus revisited. Kidney Int 65: 521-530.

10. Vesterhus P, Aarskog D (1973) Noonan's syndrome and autoimmune thyroiditis J Pediatr 83: 237-240.

11. Martin DM, Gencyuz CF, Petty EM (2001) Systemic lupus erythematosus in a man with Noonan syndrome. Am J Med Genet 102: 59-62.

12. Dall'era M (2013) Clinical features of systemic lupus erythematosus. In: Kelley's Textbook of Rheumatology, Firestein GS, Budd RC, Gabriel SE, MCinnes IA O’Dell JR (Eds), Elsevier Saunders, Philadelphia.

13. Bader-Meunier B, Cavé H, Jeremiah N, Magerus A, Lanzarotti N, et al. (2013) Are RASopathies new monogenic predisposing conditions to the development of systemic lupus erythematosus? Case report and systematic review of the literature. Semin Arthritis Rheum.

14. Doria A, laccarino L, Sarzi-Puttini P, Atzeni F, Turriel M, et al. (2005) Cardiac involvement in systemic lupus erythematosus. Lupus 14: 683-686.

15. Yamashita Y, Kusaga A, Koga Y, Nagamitsu S, Matsuishi T (2004) Noonan syndrome, moyamoya-like vascular changes, and antiphospholipid syndrome. Pediatr Neurol 31:364-366.

16. Quaio CR, Carvalho JF, da Silva CA, Bueno C, BRASil AS, et al. (2012) 
Citation: Cerpa-Cruz S, Martínez-Valles MA, Olmedo-Gaytan AG, Pérez-Lizárraga RI, Rodríguez-Cortes E, et al. (2013) Noonan Syndrome and Systemic Lupus Erythematosus: Association or Risk Factor? Int J Genomic Med 1: 107. doi:10.4172/2332-0672.1000107

Page 5 of 5

Autoimmune disease and multiple autoantibodies in 42 patients with RASopathies. Am J Med Genet A 158A: 1077-1082.

17. Roberts AE, Allanson JE, Tartaglia M, Gelb BD (2013) Noonan syndrome. Lancet 381: 333-342.

18. Mustelin T, Vang T, Bottini N (2005) Protein tyrosine phosphatases and the immune response. Nat Rev Immunol 5: 43-57.

19. Vang T, Miletic AV, Bottini N, Mustelin T (2007) Protein tyrosine phosphatase PTPN22 in human autoimmunity. Autoimmunity 40: 453-461.

20. Deapen D, Escalante A, Weinrib L, Horwitz D, Bachman B, et al. (1992) A revised estimate of twin concordance in systemic lupus erythematosus. Arthritis Rheum 35: 311-318.

21. Mustelin T (2006) Are other protein tyrosine phosphatases than PTPN22 associated with autoimmunity? Semin Immunol 18: 254-260.

22. Crow YJ (2011) Lupus: how much "complexity" is really (just) genetic heterogeneity? Arthritis Rheum 63: 3661-3664.
23. Vang T, Miletic AV, Arimura Y, Tautz L, Rickert RC, et al. (2008) Protein tyrosine phosphatases in autoimmunity. Annu Rev Immunol 26: 29-55.

24. Nath SK, Quintero-Del-Rio Al, Kilpatrick J, Feo L, Ballesteros M, et al. (2004) Linkage at 12q24 with systemic lupus erythematosus (SLE) is established and confirmed in Hispanic and European American families. Am J Hum Genet 74 73-82

25. Alanay Y, Balci S, Ozen S (2004) Noonan syndrome and systemic lupus erythematosus: presentation in childhood. Clin Dysmorphol 13: 161-163.

26. Lopez-Rangel E, Malleson PN, Lirenman DS, Roa B, Wiszniewska J, et al. (2005) Systemic lupus erythematosus and other autoimmune disorders in children with Noonan syndrome. Am J Med Genet A 139: 239-242.

27. Lisbona MP, Moreno M, Orellana C, Gratacos J, Larrosa M (2009) Noonan syndrome associated with systemic lupus erythematosus. Lupus 18: 267-269.

28. Leventopoulos G, Denayer E, Makrythanasis P, Papapolychroniou C, Fryssira $\mathrm{H}$ (2010) Noonan syndrome and systemic lupus erythematosus in a patient with a novel KRAS mutation. Clin Exp Rheumatol 28: 556-557. 